\title{
Wettability of Methacrylate Copolymer Films Deposited on Anodically Oxidized and Roughened Aluminium Surfaces
}

\author{
Ralf Frenzel $^{\mathrm{a}, *}$, Christa Blank $^{\mathrm{b}}$, Karina Grundke ${ }^{\mathrm{a}}$, Veneta Hein ${ }^{\mathrm{b}}$, Bernd Schmidt $^{\mathrm{c}}$, \\ Frank Simon $^{\mathrm{a}}$, Michael Thieme ${ }^{\mathrm{b}}$ and Hartmut Worch ${ }^{\mathrm{b}}$ \\ ${ }^{a}$ Leibniz Institute of Polymer Research Dresden, Hohe Str. 6, D-01069 Dresden, Germany \\ ${ }^{\mathrm{b}}$ Technische Universität Dresden, Institute of Material Science, D-01062 Dresden, Germany \\ ${ }^{c}$ Nehlsen-BWB Flugzeuggalvanik Dresden GmbH \& Co. KG, Grenzstr. 2, D-01109 Dresden, \\ Germany
}

\begin{abstract}
The wetting behavior of water on methacrylate copolymer film was studied on anodically oxidized and micro-roughened aluminium surfaces and also on smooth model surfaces. The copolymerization of tertbutyl methacrylate with a methacrylate containing a f uoroorganic side chain led to a considerable decrease of the surface free energy, but not to a superhydrophobic behavior of polymer-coated, micro-roughened aluminium surfaces. However, copolymers containing both hydrophobic and hydrophilic sequences are able to form superhydrophobic $\mathrm{flms}$. X-ray photoelectron spectroscopy showed that an enrichment of the interface between the solid phase and the air by f uorine-containing polymer components was the reason for the strong decrease of the surface free energy. The hydrophilic segments of the copolymers improved the ability to wet the highly polar aluminium surface and to form $\mathrm{flms}$ of higher density.
\end{abstract}

Keywords

Methacrylic copolymers, wetting behavior, superhydrophobicity, aluminium, roughening, coating, XPS, surface segregation

\section{Introduction}

The wetting behavior of solid surfaces is primarily determined by the chemical and morphological characteristics of the surface and less by their bulk characteristics. For this reason, it is possible to impart intrinsically hydrophilic metal and metal oxide surfaces a hydrophobic behavior. A water drop on a smooth hydrophobic surface has a maximum contact angle between $90^{\circ}$ and approximately $120^{\circ}$ for a layer of densely packed trifluoromethy groups, which minimize the surface free energy [1]. With roughening of the surface the static contact angle is increased according

\footnotetext{
${ }^{*}$ To whom correspondence should be addressed. Tel.: +351-4658-539; Fax: +351-4658-214; e-mail: frenzelr@ipfdd.de
} 
to the model of Wenzel [2]. With further increasing roughness an abrupt change of the wetting behavior takes place: a phenomenon which was firs observed by Dettre and Johnson [3]. Water drops on such surfaces have an approximately spherical form and roll off completely just by a slight tilt. An interpretation of this complete dewetting was given by Cassie and Baxter [4]. The wetting behavior changes from a homogeneous to a heterogeneous regime. The increased capillary forces prevent now the exchange of air for water in the cavities. Thus, the effective contact area between the solid and the liquid phase is limited only to the spikes of surface topography; hence, the adhesion forces are minimized and the result of this change is superhydrophobicity [5,6]. Superhydrophobic surfaces (also called ultrahydrophobic or super water-repellent surfaces, cf. recent reviews in [6-10]) can be created by the combination of materials with low surface free energy and an adequately rough surface topography. Contact angle measurements can be considered as a quantitative measure to characterize the superhydrophobic effect. Both advancing (contact angles measured in dependence on increasing the water droplet volume, $\theta_{\mathrm{a}}$ ) and receding contact angles (measured in dependence on decreasing the water droplet volume, $\theta_{\mathrm{r}}$ ) have to be higher than $150^{\circ}$.

On aluminium surfaces it is possible to create a suitable micro-rough structure using an electrochemical anodization process [11-13]. In this process the electrochemical formation of the aluminium oxide layer is combined with its partial dissolution by an acid electrolyte solution.

For hydrophobization of already roughened surfaces different concepts have been developed. Mostly, a low surface free energy was aimed by depositing a dense fil exposing methyl or trifluoromethy groups at the interface to the air. Hydrophobic self-assembled monolayers of monoalkyl phosphoric acids [11] or alkyl phosphonic acids [14] were successfully applied to endow aluminium oxide surfaces with superhydrophobic properties. The phosphorus containing functional groups anchor the long alkyl-tail molecules on the aluminium oxide surface. The anchoring of alkyl thiols [15] requires a pre-coating of a precious metal. To generate superhydrophobicity by anchoring a fil of stearic acid a pre-coating of poly(ethylene imine) was used [16]. But also without such a pre-coating stearic acid forms a superhydrophobic $\mathrm{f} \mathrm{lm}$ on an etched aluminium surface [17]. Trifunctional alkylsilanes [11] with the potential to form cross-linked networks are also suitable to obtain superhydrophobic aluminium oxide surfaces. However, monomolecular thin f lms cannot be considered as a stable coating. Monofunctional molecules can be easily desorbed by breaking only one bond to the substrate. Slight mechanical stress or traces of water, which is present in the oxide layer of the substrate material, can promote lateral coating delamination.

Alternatively, it is possible to apply polymer film for this purpose. Of course, such polymers must also have the ability to strongly reduce the surface free energy. Fluorine-containing polymers appear to be suitable to endow metal oxide surfaces with superhydrophobic properties, but most of them are insoluble. An exception is Tef on ${ }^{\circledR}$ AF, which can be dissolved in perfluorinate solvents and applied by spin- 
coating. Superhydrophobic $\mathrm{flms}$ were also obtained from polysulfones [18], which were partially fluorinate in the side chains. Some of them are soluble in common organic solvents.

Here, we employed polymethacrylates to provide the roughened and oxidized surface of aluminium sheets with superhydrophobic properties. Polymethacrylates can be easily synthesized and their properties varied by copolymerization of methacrylate monomers that have different side chains. The correlation between the structural composition of polymethacrylates and their wetting behavior is well known from model studies carried out on thin film on smooth surfaces $[19,20]$, but there is no information about the wetting behavior of polymethacrylate $\mathrm{flms}$ on micro-rough surfaces. We have synthesized poly(tert-butyl methacrylate) and poly(methyl methacrylate) containing different hydrophobic and hydrophilic sequences. In dependence on the polymer composition the wetting behavior was studied on polymer-coated smooth silicon wafers and rough aluminium surfaces.

\section{Experimental}

\subsection{Materials}

Pieces $(26 \mathrm{~mm} \times 38 \mathrm{~mm} \times 1 \mathrm{~mm})$ of commercially available aluminium sheets (Al Mg1, EN AW-5005) were cleaned by pickling in $1 \mathrm{~mol} / 1 \mathrm{NaOH}$ for $10 \mathrm{~min}$ at room temperature. In order to neutralize residual traces of $\mathrm{NaOH}$ the pieces were dipped in diluted $\mathrm{HNO}_{3}(1 \mathrm{~mol} / \mathrm{l})$, kept there for $1 \mathrm{~min}$ at room temperature and rinsed with de-ionized water. The anodic oxidation of the samples was carried out in a double-walled electrolysis cell (Korrosionsmesszelle KMZ 5/S, Sensortechnik Meinsberg $\mathrm{GmbH}$, Meinsberg, Germany) fille with diluted sulfuric acid and dissolved $\mathrm{Al}_{2}\left(\mathrm{SO}_{4}\right)_{3}\left(\left[\mathrm{SO}_{4}{ }^{2-}\right]=2.3 \mathrm{~mol} / \mathrm{l}\right)$ as the electrolyte. The anodic oxidation was performed for $25 \mathrm{~min}$ at $(40 \pm 1)^{\circ} \mathrm{C}$, and a current density of $i=28 \mathrm{~mA} / \mathrm{cm}^{2}$. The oxidized and roughened samples were carefully rinsed with tap water ( $7 \mathrm{~min}$ ) and rinsed two times with de-ionized water. Finally, the samples were dried. More details regarding the anodic oxidation and roughening of the aluminium sheets are given in Refs $[12,13]$.

The copolymers were synthesized by radical initiated copolymerization of methacrylate monomers in butanone under inert conditions (dry nitrogen atmosphere). As initiator 2,2'-azobis-(2-methyl propionitrile) (AIBN) was employed. The copolymers obtained were used without further purification The following example to produce the copolymer poly[methyl methacrylate-co-Zonyl ${ }^{\circledR}$ TM-co-2(methacryloyloxy)ethyl acetoacetate] (Table 1, polymer 21b) from three monomers illustrates the typical synthesis:

$100 \mathrm{mg}$ of AIBN (Fluka, Sigma-Aldrich Chemie GmbH, Taufkirchen, Germany) were placed in a $100 \mathrm{ml}$ three-necked round-bottom $\mathrm{f}$ ask equipped with a reflu condenser and a dropping funnel containing $50 \mathrm{ml}$ butanone. $8 \mathrm{ml}$ MMA (methyl methacrylate, Merck KgaA, Darmstadt, Germany), 1 ml AAEA [2(methacryloyloxy)ethyl acetoacetate, Lonza Ltd., Basel, Switzerland], $1 \mathrm{ml}$ Zonyl ${ }^{\circledR}$ 
Table 1.

Methacrylate polymers and copolymers employed to coat anodically oxidized and roughened aluminium sheets. The structures of the polymers are shown in Fig. 1

\begin{tabular}{|c|c|}
\hline $\begin{array}{l}\text { Sample } \\
\text { number }\end{array}$ & Polymer \\
\hline $10 \mathrm{a}$ & Poly (tert-butyl methacrylate) (PtBMA) \\
\hline $10 \mathrm{~b}$ & Poly(tert-butyl methacrylate-co-Zonyl $\left.{ }^{\circledR} \mathrm{TM}\right), 9: 1$ \\
\hline $11 \mathrm{a}$ & Poly[tert-butyl methacrylate-co-2-(methacryloyloxy)ethyl acetoacetate], 9:1 \\
\hline $11 \mathrm{~b}$ & $\begin{array}{l}\text { Poly[tert-butyl methacrylate-co-Zonyl }{ }^{\circledR} \text { TM-co-2-(methacryloyloxy)ethyl acetoacetate], } \\
8: 1: 1\end{array}$ \\
\hline $12 \mathrm{a}$ & Poly(tert-butyl methacrylate-co-2-hydroxyethyl methacrylate), 9:1 \\
\hline $12 b$ & Poly $\left(\right.$ tert-butyl methacrylate-co-Zonyl ${ }^{\circledR}$ TM-co-2-hydroxyethyl methacrylate), 8:1:1 \\
\hline 20a & Poly(methyl methacrylate) (PMMA) \\
\hline $20 \mathrm{~b}$ & Poly(methyl methacrylate-co-Zonyl $\left.{ }^{\circledR} \mathrm{TM}\right), 9: 1$ \\
\hline 21a & Poly[methyl methacrylate-co-2-(methacryloyloxy)ethyl acetoacetate], 9:1 \\
\hline $21 b$ & $\begin{array}{l}\text { Poly[methyl methacrylate-co-Zonyl }{ }^{\circledR} \text { TM-co-2-(methacryloyloxy)ethyl acetoacetate], } \\
\text { 8:1:1 }\end{array}$ \\
\hline $22 \mathrm{a}$ & Poly(methyl methacrylate-co-2-hydroxyethyl methacrylate), 9:1 \\
\hline $22 b$ & Poly(methyl methacrylate-co-Zonyl ${ }^{\circledR}$ TM-co-2-hydroxyethyl methacrylate), 8:1:1 \\
\hline
\end{tabular}

TM [Zonyl ${ }^{\circledR} \mathrm{TM}$ is a mixture of 2-(perfluoroal yl)ethyl methacrylates, Aldrich, Sigma-Aldrich Chemie GmbH, Taufkirchen, Germany], and $10 \mathrm{ml}$ butanone were added with a syringe. The mixture was stirred using a magnetic stirrer. The apparatus was purged with dry nitrogen (purity grade 6.0, Messer Group GmbH, Sulzbach, Germany) for $15 \mathrm{~min}$. Then, the reaction mixture was warmed up in a water bath to $60^{\circ} \mathrm{C}$. During the polymerization reaction the solution became more and more viscous. In order to keep the reaction volume constant, the slight loss of butanone in the reaction solution was compensated by adding butanone from the dropping funnel. Nevertheless, after some time, the mixture could not be stirred. To increase the polymerization degree the temperature was maintained for $6 \mathrm{~h}$, whereupon the mixture was allowed to cool down overnight. Then, the viscous polymer was dissolved by adding the remaining butanone and warming up. The polymer solution was diluted with additional butanone to yield $100 \mathrm{ml}$. For characterization of the polymer $10 \mathrm{ml}$ of the solution were dissolved in $40 \mathrm{ml}$ tetrahydrofuran (THF, Fluka/SigmaAldrich Chemie $\mathrm{GmbH}$, Taufkirchen, Germany) and added to $11 n$-hexane drop by drop. The precipitate was fltered off and washed with $n$-hexane. The yield of the copolymer was $1.58 \mathrm{~g}(77.4 \%)$. The molecular weight of the polymer was $M_{\mathrm{W}}=350,000 \mathrm{~g} / \mathrm{mol}$ and its polydispersity was $M_{\mathrm{w}} / M_{\mathrm{n}}=6$.

Copolymers containing tBMA (tert-butyl methacrylate) monomer units yielded oily products which could not be precipitated as a solid.

Table 1 summarizes the polymers synthesized to be applied as a coating material. The ratios after the polymer names indicate the volume proportions of the copoly- 


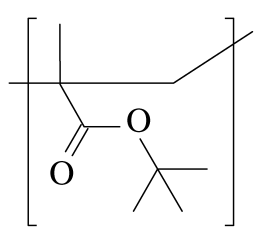

(a)

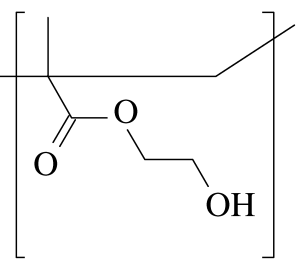

(d)

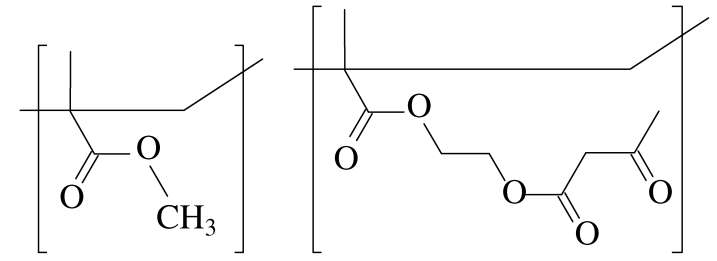

(b)

(c)

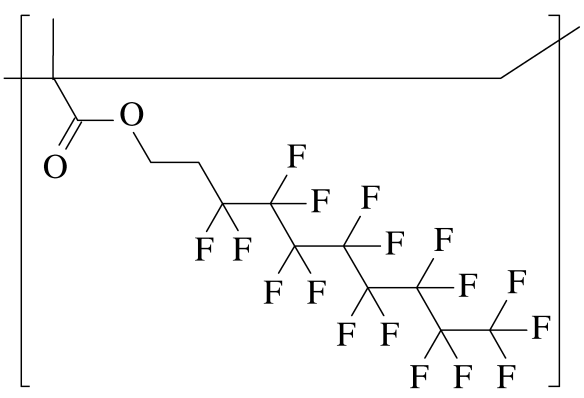

(e)

Figure 1. Chemical structures of functional sequences of the methacrylate polymers and copolymers employed to equip anodically oxidized and roughed aluminium surfaces, glass and smooth silicon wafers to control their wetting behavior: tert-butyl methacrylate sequence (a), methyl methacrylate sequence (b), 2-(methacryloyloxy)ethyl acetoacetate sequence (c), 2-hydroxyethyl methacrylate sequence $(\mathrm{d})$, and Zonyl ${ }^{\circledR}$ TM sequence (e).

merized monomers. The compound numbers 10-12 refer to tBMA, and 20-22 to MMA. Numbers designated by ' $a$ ' stand for fluorine-fre copolymers, and with ' $b$ ' for Zonyl ${ }^{\circledR}$ TM-containing copolymers. The chemical structures of the sequences of the methacrylic polymers and copolymers are shown in Fig. 1.

\subsection{Coating}

For coating the anodically oxidized and roughened aluminium sheets, dilute polymer solutions with $1 \%$ concentration in 2-butanone were applied without purifi cation of the polymers synthesized as described above. The dry aluminium sheets were dipped in the polymer solution and kept there for $1 \mathrm{~h}$. The coated samples were dried overnight and heated in an oven at $120^{\circ}$ for $1 \mathrm{~h}$.

In addition to the anodized aluminium specimens, commercially available glass plates for microscopic studies and thermally oxidized silicon wafers $(20 \mathrm{~mm} \times$ $20 \mathrm{~mm}$ pieces with a hole) were also coated for model experiments. These hydrophilic materials were ultrasonically cleaned in ethanol (analytical grade, $10 \mathrm{~min}$ ). Thick polymer film on glass plates were formed by solvent evaporation of the polymer solution $(10 \%)$. The wafers were spin-coated (solution of $1 \%$ polymer in 2-butanone, $2000 \mathrm{~min}^{-1}, 30 \mathrm{~s}$ ) and heated at $120^{\circ} \mathrm{C}$ for $1 \mathrm{~h}$. Typical thicknesses of these layers were about $50 \mathrm{~nm}$. 


\subsection{Scanning Electron Microscopy (SEM)}

To record images of the micro-rough aluminium surface, a Zeiss DSM 982 Gemini microscope with a feld emission cathode was used at low acceleration voltage $(2 \mathrm{keV})$ and appropriate working distance. Top view images were recorded from $35^{\circ}$ tilted samples. Additionally, cross-sections were prepared for observing the topography/roughness, the thickness and the homogeneity of the oxide layer.

\subsection{X-ray Photoelectron Spectroscopy (XPS)}

All XPS studies were carried out using of an AXIS ULTRA photoelectron spectrometer (KRATOS ANALYTICAL, Manchester, England). The spectrometer was equipped with a monochromatic $\mathrm{Al} \mathrm{K}_{\alpha}\left(h_{\nu}=1486.6 \mathrm{eV}\right)$ X-ray source of $300 \mathrm{~W}$ at $15 \mathrm{kV}$. The kinetic energy of the photoelectrons was determined with a hemispherical analyzer set to a pass energy of $160 \mathrm{eV}$ for wide-scan spectra and $20 \mathrm{eV}$ for high-resolution spectra. During all measurements electrostatic charging of the sample was compensated by means of a low-energy electron source working in combination with a magnetic immersion lens. Later, all recorded peaks were shifted by the same amount which was necessary to set the $\mathrm{C}_{1 \mathrm{~s}}$ peak to $285.00 \mathrm{eV}$ for saturated hydrocarbons [21]. For all XPS measurements the take-off angle define as the angle between the sample surface normal and the direction of electron extraction was $0^{\circ}$. On smooth surfaces the maximum information depth of the XPS method was less than $10 \mathrm{~nm}$.

Quantitative elemental compositions were determined from the peak areas using experimentally determined sensitivity factors and the spectrometer transmission function. Background spectrum was subtracted according to Shirley [22]. The highresolution spectra were deconvoluted using a computer routine. Free parameters of component peaks used were their binding energy (BE), height, full width at half maximum, and the Gaussian-Lorentzian ratio.

\subsection{Contact Angle Measurements}

All contact angles were measured by sessile drop experiments as advancing $\left(\theta_{\mathrm{a}}\right)$ and receding contact angles $\left(\theta_{\mathrm{r}}\right)$. The advancing contact angle is the maximum contact angle which is determined upon increasing the droplet volume, whereas the receding contact angle is the minimum contact angle which can be measured by decreasing the droplet volume.

In the case of coated aluminium samples, contact angles were measured using a Drop Shape Analysis System DSA 10 (KRÜSS Optronic GmbH, Hamburg, Germany). Droplets of de-ionized water (surface tension $72.8 \mathrm{mN} / \mathrm{m}$ at $23^{\circ} \mathrm{C}$ ) were placed with a motor-driven syringe onto the sample surface. The syringe was kept in the droplet during the contact angle measurement. The software option Tangente 2 was used to analyze the shape of the droplet and calculate the corresponding contact angle.

The contact angle values given here are mean values of $f$ ve individual measurements carried out on different locations on the sample surface. 
In order to determine the intrinsic Young's contact angle values and the surface free energies of the polymers and copolymers, contact angle measurements were carried out on silicon wafers which were coated with smooth $\mathrm{f} l \mathrm{~ms}$ of the polymers and copolymers. Here the contact angles were measured by the ADSA-P (axisymmetric drop shape analysis-profile contact angle technique [23, 24]. Advancing and receding contact angles of sessile liquid droplets were measured by pumping liquid steadily into the sessile drop from below the wafer surface through the hole using a motorized syringe mechanism. Details of the methodology and experimental setup can be found elsewhere [23]. ADSA-P determines the contact angle, surface tension, drop volume, and surface area of the sessile droplets. The surface free energy $\left(\gamma_{\mathrm{sv}}\right)$ was calculated according to the Equation-of-State approach for solid/liquid interfacial tensions [25].

\section{Results and Discussion}

Figure 2 shows the topography of an anodically oxidized and roughened aluminium sample. "Mountain ridges" with a middle height of ca. $2 \mu \mathrm{m}$ are homogeneously distributed over the whole sample surface. The magnifie image (Fig. 2b) clearly shows an additional roughness feature on the nanometer scale. The two-tier scale of microscopic and nanoscopic roughness is typical for the Lotus leaf showing superhydrophobic properties [26], and it is undisputed that a topography like this one is advantageous for the superhydrophobic effect. The sample cross-section in Fig. 2c shows a dense aluminium oxide layer without any pore defects on the $\mu \mathrm{m}$ scale. This oxide type is characterized by a f ne column-like structure provided with nano-pores of about $50 \mathrm{~nm}$ in diameter $[13,27]$. The oxide layer protects the metallic aluminium substrate against corrosive attack and is the support for the polymer layer applied to lower the surface free energy.

The application of the coatings by dipping the roughened aluminium samples in a diluted polymer solution seems to be suitable and effective to provide large aluminium sheets with superhydrophobic surface properties. Coating $\mathrm{flms}$ to control the surface properties, e.g. the wetting behavior, and to prevent metal substrate

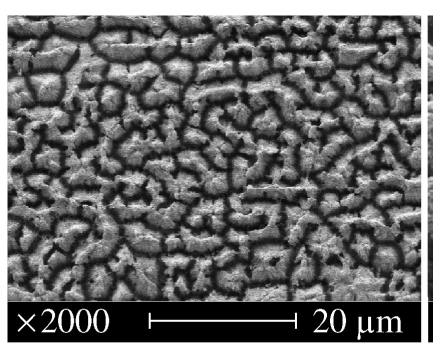

(a)

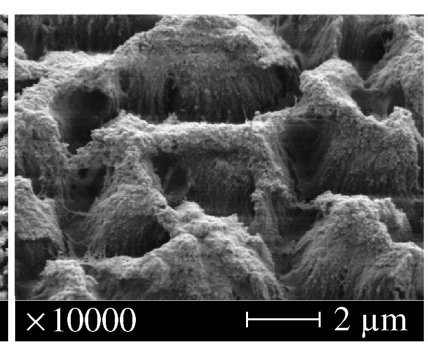

(b)

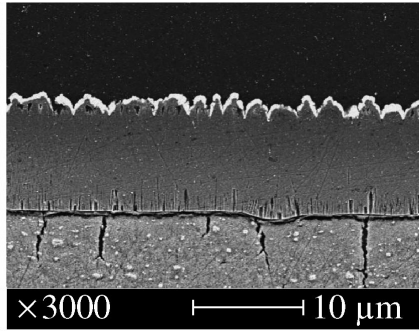

(c)

Figure 2. SEM images of an anodically oxidized and roughened aluminium substrate. Top view (a), tilted $\left(35^{\circ}\right)$ and magnifie image (b), and polished cross-section (c). 
corrosion must be completely close packed and dense. However, in order to obtain superhydrophobic surface properties the thickness of the coating $\mathrm{flms}$ must be thin enough to replicate the anodically roughened oxide surface without fillin up their cavities.

The aluminium samples modifie by methacrylate copolymer film were investigated by XPS to obtain their chemical surface composition. Besides the elements of the copolymer fil (carbon, fluorine also the elements of the oxidic substrate material (aluminium and sulphur) were detected. The detection of aluminium indicates a very thin copolymer layer or a ruptured copolymer film which did not fully cover the substrate material. Traces of sulphur (found as sulphate $\mathrm{SO}_{4}{ }^{2-}$ ) were incorporated during the anodization process. Both layers contained oxygen, but it was less in the polymer fil than in the oxide layer. To calculate the degree of coverage, $\phi$ the relative atomic concentration (at $\%$ ) of carbon (the key element of the polymer layer) was related to the sum of the relative atomic concentrations of carbon and aluminium (the key element of the substrate material):

$$
\phi=\frac{[\mathrm{C}]}{[\mathrm{C}]+[\mathrm{Al}]} .
$$

The XPS investigations showed distinct differences in the degrees of coverage (Tables 2 and 3). Pure poly(tert-butyl methacrylate) (PtBMA) flms are characterized by low values of the degree of coverage. Obviously, these film did not fully cover the substrate oxide layer. The reason for the formation of heterogeneous polymer film is the partial wetting of the strongly hydrophilic and water containing aluminium oxide layer by the intrinsically hydrophobic polymer. Of course, such heterogeneous polymer film are unsuitable to endow rough substrate materials with superhydrophobic properties. Surprisingly, poly(methyl methacrylate) (PMMA), a polymer with a distinctly higher surface energy also formed coating film having a low degree of coverage. The copolymerization of tBMA and MMA with $10 \mathrm{vol} \%$ of methacrylates having a polar functional side group (e.g. samples 11a, 12a, 21a and 22a) gave polymers which were able to wet the substrate oxide

Table 2.

Relative atomic concentrations (at\%) determined by XPS of anodically oxidized and roughened aluminium sheets coated with tert-butyl methacrylate based polymer film and the degrees of coverage $\phi$ calculated according to equation (1)

\begin{tabular}{llllll}
\hline Polymer & {$[\mathrm{C}]$} & {$[\mathrm{O}]$} & {$[\mathrm{Al}]$} & {$[\mathrm{Al}] /[\mathrm{C}]$} & $\phi$ \\
\hline $10 \mathrm{a}$ & 16.2 & 60.4 & 20.5 & 1.27 & 0.44 \\
$10 \mathrm{~b}$ & 17.2 & 58.4 & 20.6 & 1.19 & 0.46 \\
$11 \mathrm{a}$ & 37.6 & 46.7 & 14.6 & 0.39 & 0.72 \\
$11 \mathrm{~b}$ & 31.9 & 46.9 & 14.6 & 0.46 & 0.69 \\
$12 \mathrm{a}$ & 37.8 & 46.0 & 15.0 & 0.40 & 0.72 \\
$12 \mathrm{~b}$ & 40.5 & 38.6 & 13.5 & 0.33 & 0.75 \\
\hline
\end{tabular}


layer and form more closely packed and more homogeneous coating $\mathrm{flms}$. Further, additionally copolymerized monomers containing fluorinate alkyl side chains (samples 11b, 12b, 21b and 22b), which should increase the polymers' hydrophobicity, but still showed a high degree of coverage. To explain this phenomenon, XPS model studies were carried out on polymer coating flms applied on smooth glass surfaces. As for its hydrophilicity the glass surface can be compared to the oxide layer of the anodically oxidized aluminium. Hence, the wetting regime and interactions of the polymer with these substrates should be similar. Figures 3 and 4 show XPS wide-scan spectra of these two copolymer films Before their analysis the copolymer film were carefully removed from the glass substrates and then XPS spectra of the copolymer/air and copolymer/glass interfaces were recorded.

\section{Table 3.}

Relative atomic concentrations (at \%) determined by XPS of anodically oxidized and roughened aluminium sheets coated with methyl methacrylate based polymer film and the degrees of coverage $\phi$ calculated according to equation (1)

\begin{tabular}{llllll}
\hline Polymer & {$[\mathrm{C}]$} & {$[\mathrm{O}]$} & {$[\mathrm{Al}]$} & {$[\mathrm{Al}] /[\mathrm{C}]$} & $\phi$ \\
\hline $20 \mathrm{a}$ & 17.5 & 60.0 & 20.3 & 1.16 & 0.46 \\
$20 \mathrm{~b}$ & 19.6 & 56.7 & 19.1 & 0.97 & 0.51 \\
$21 \mathrm{a}$ & 42.0 & 44.9 & 11.9 & 0.28 & 0.78 \\
$21 \mathrm{~b}$ & 37.5 & 42.9 & 12.5 & 0.33 & 0.75 \\
$22 \mathrm{a}$ & 54.8 & 38.2 & 6.2 & 0.11 & 0.90 \\
$22 \mathrm{~b}$ & 33.6 & 46.9 & 13.3 & 0.39 & 0.72 \\
\hline
\end{tabular}

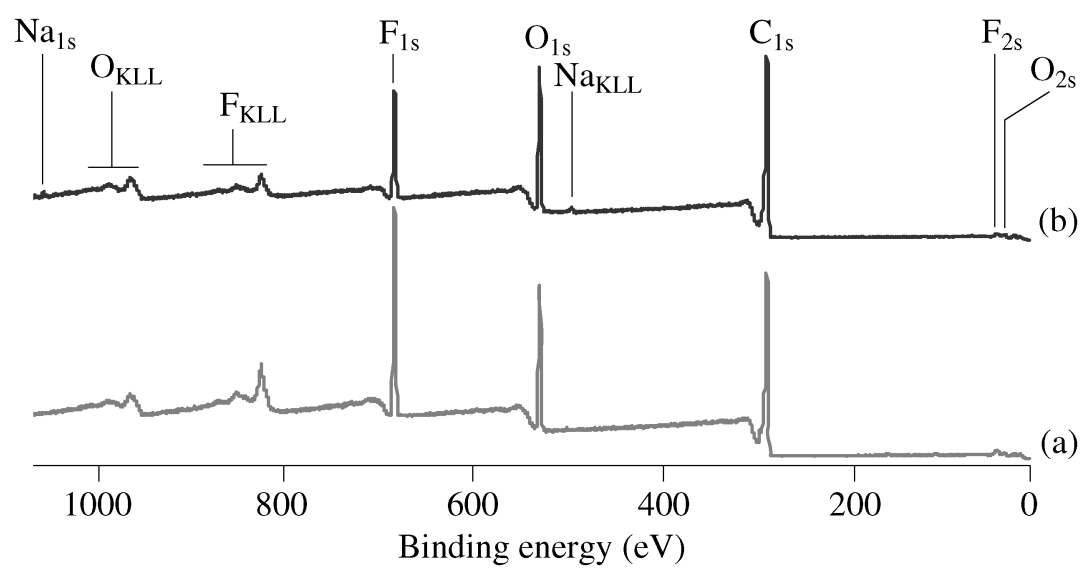

Figure 3. XPS wide-scan spectra of a poly[tert-butyl methacrylate-co-Zonyl ${ }^{\circledR}$ TM-co-2(methacryloyloxy)ethyl acetoacetate], 8:1:1 fil (polymer 11b) removed from a glass substrate. Spectrum (a) was recorded from the copolymer side which was directed towards the air, while spectrum (b) refers to the copolymer side which was in contact with the glass substrate. The atomic concentrations are given in Table 4. 


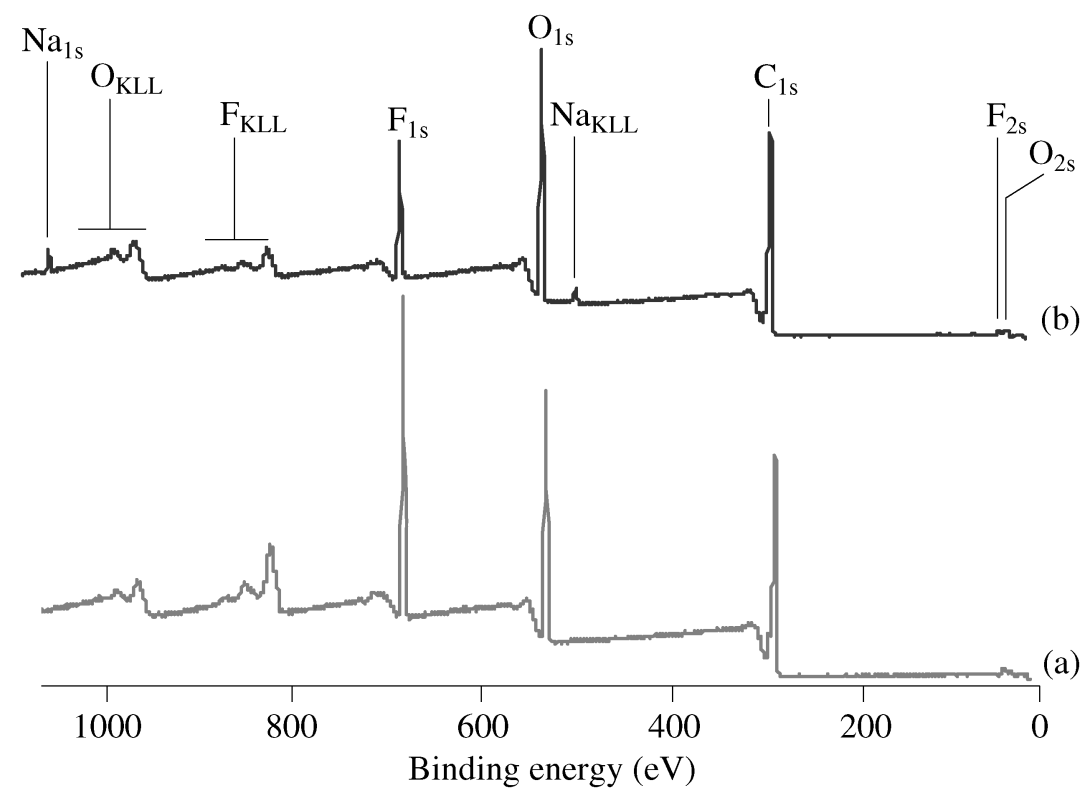

Figure 4. XPS wide-scan spectra of a poly[methyl methacrylate-co-Zonyl ${ }^{\circledR}$ TM-co-2(methacryloyloxy)ethyl acetoacetate], 8:1:1 fil (polymer 21b) removed from a glass substrate. Spectrum (a) was recorded from the copolymer side which was directed towards the air, while spectrum (b) refers to the copolymer side which was in contact with the glass substrate. The atomic concentrations are given in Table 5 .

Table 4.

Relative atomic concentrations (at\%) determined by XPS of a poly[tert-butyl methacrylate-co-Zonyl ${ }^{\circledR}$ TM-co-2-(methacryloyloxy)ethyl acetoacetate], 8:1:1 fil (polymer 11b) which was in contact with air and glass

\begin{tabular}{lllll}
\hline Element & {$[\mathrm{C}]$} & {$[\mathrm{O}]$} & {$[\mathrm{F}]$} & {$[\mathrm{F}]:[\mathrm{C}]$} \\
\hline Polymer/Air & 70.6 & 15.6 & 13.9 & 0.197 \\
Polymer/Glass & 75.3 & 17.1 & 7.6 & 0.101 \\
\hline
\end{tabular}

As can be clearly seen in Figs 3 and 4 the relative fluorin content or the $[\mathrm{F}]:[\mathrm{C}]$ ratio depends on the phase which was in contact with the copolymer film Fluorinecontaining groups are concentrated on the side which was in contact with the air. In the case of sample $11 \mathrm{~b}$ nearly twice the fluorin content was found (Table 4). For the methyl methacrylate copolymer (sample 21b) this behavior was even more pronounced (Table 5).

The sides which were in contact with the glass substrate showed only a slightly increased oxygen content relative to carbon, but showed a pronounced increase relative to f uorine, the key element for the strongly hydrophobic alkyl side chains. Obviously, the copolymer molecules and their sequences were subjected to a pref- 
Table 5.

Relative atomic concentrations (at \%) determined by XPS of a poly[methyl methacrylate-co-Zonyl ${ }^{\circledR}$ TM-co-2-(methacryloyloxy)ethyl acetoacetate], 8:1:1 fil (polymer 21b) which was in contact with air and glass

\begin{tabular}{lllcc}
\hline Element & {$[\mathrm{C}]$} & {$[\mathrm{O}]$} & {$[\mathrm{F}]$} & {$[\mathrm{F}]:[\mathrm{C}]$} \\
\hline Polymer/Air & 66.9 & 18.9 & 14.3 & 0.213 \\
Polymer/Glass & 69.5 & 22.8 & 7.0 & 0.101 \\
\hline
\end{tabular}

erential orientation, which was controlled by the contacting phase. Sequences lowering the surface free energy, e.g. fluorinate alkyl chains, segregate to the copolymer/air interface and are concentrated there. Hydrophilic parts are preferentially oriented towards the copolymer/oxide interface. This enables a better wetting of the oxide layer during the coating process and leads to more closely packed and more homogeneous copolymer films as indicated by a high degree of coverage.

Of course, the molecular orientation and the properties of the polymer and copolymer film control the surface wettability by water. Additionally, it is noteworthy that XPS measurements on coated aluminium samples did not show any traces of silicon. This ensure that polysiloxanes were absent and did not prevent the wetting by water. In the case of polymer-coated silicon wafers the absence of silicon signals also indicates that the coating f $1 \mathrm{~ms}$ were closed and dense.

Contact angle measurements on thin copolymer film applied onto smooth silicon wafer surfaces showed that the intrinsic contact angle values are strongly influence by the co-monomer containing fluorinate or more polar side chains. The corresponding surface free energies of these copolymers also showed, compared to the homopolymers (PtBMA 10a and PMMA 20a) a strong influenc of the f uorine-containing hydrophobic sequences. Remarkably, all copolymers having f uorine-containing sequences had surface free energy values about $20 \mathrm{~mJ} / \mathrm{m}^{2}$, almost independent of other co-monomers (Tables 6 and 7).

The observed wetting behavior of the coated rough aluminium surfaces did not show a strong correlation with the surface free energies of the polymers which were calculated from contact angles measured on smooth polymer-coated silicon wafers. The superhydrophobic behavior, which was expected for hydrophobic polymer coatings on rough surfaces, was only observed for samples coated with copolymers containing also hydrophilic sequences in the molecule, whereas purely hydrophobic homopolymers and copolymers without any hydrophilic sequences (e.g. samples 10a, 10b) did not lead to superhydrophobic surfaces (Tables 6 and 7). Rather, these systems were wetted by water. This was a very surprising fnding because it was expected that only those polymers having a high number of nonpolar sequences, such as tert-butyl or fluorinate side chains were able to lower the surface free energy significantl and thus prevent wetting by polar liquids. This unexpected behavior results from an incomplete $\mathrm{flm}$ formation of these polymers 
Table 6.

Water contact angles (advancing contact angle $\theta_{\mathrm{a}}$ and receding contact angle $\theta_{\mathrm{r}}$ ) on tert-butyl methacrylate based copolymers on anodically oxidized and roughened aluminium sheets (measured by DSA 10 instrument) and on smooth silicon wafers (measured by axisymmetric drop shape analysisprofil ADSA-P [22]). The surface free energy $\gamma_{\mathrm{sv}}$ was calculated for the polymer-coated wafers using the Equation-of-State approach [23]

\begin{tabular}{|c|c|c|c|c|c|}
\hline \multirow[t]{2}{*}{ Polymer } & \multicolumn{2}{|c|}{ A1 Mg1 (rough) } & \multicolumn{2}{|c|}{ Silicon wafer (smooth) } & \multirow{2}{*}{$\begin{array}{l}\gamma_{\mathrm{sv}} \\
\left(\mathrm{mJ} / \mathrm{m}^{2}\right)\end{array}$} \\
\hline & $\theta_{\mathrm{a}}\left(^{\circ}\right)$ & $\theta_{\mathrm{r}}\left(^{\circ}\right)$ & $\theta_{\mathrm{a}}\left(^{\circ}\right)$ & $\theta_{\mathrm{r}}\left(^{\circ}\right)$ & \\
\hline 10a & 33 & $0^{*}$ & 90.9 & 81.0 & 28.7 \\
\hline $10 \mathrm{~b}$ & 64 & $0^{*}$ & 104.6 & 82.8 & 20.3 \\
\hline $11 \mathrm{a}$ & 153 & 150 & 88.9 & 78.6 & 29.9 \\
\hline $11 \mathrm{~b}$ & 153 & 151 & 103.3 & 80.2 & 21.0 \\
\hline $12 a$ & 147 & $0^{*}$ & 88.4 & 72.7 & 30.2 \\
\hline $12 b$ & 153 & 150 & 103.4 & 76.7 & 21.0 \\
\hline
\end{tabular}

* Wetted by water.

Table 7.

Water contact angles (advancing contact angle $\theta_{\mathrm{a}}$ and receding contact angle $\theta_{\mathrm{r}}$ ) on methyl methacrylate-based copolymers film deposited on anodically oxidized and roughened aluminium sheets (measured by DSA 10 instrument) and on smooth silicon wafers (measured by axisymmetric drop shape analysis-profil ADSA-P [22]). The surface free energy $\gamma_{\mathrm{sv}}$ was calculated for the polymer-coated wafers using the Equation-of-State approach [23]

\begin{tabular}{|c|c|c|c|c|c|}
\hline \multirow[t]{2}{*}{ Polymer } & \multicolumn{2}{|c|}{ Al Mg1 (rough) } & \multicolumn{2}{|c|}{ Silicon wafer (smooth) } & \multirow{2}{*}{$\begin{array}{l}\gamma_{\mathrm{sv}} \\
\left(\mathrm{mJ} / \mathrm{m}^{2}\right)\end{array}$} \\
\hline & $\theta_{\mathrm{a}}\left({ }^{\circ}\right)$ & $\theta_{\mathrm{r}}\left({ }^{\circ}\right)$ & $\theta_{\mathrm{a}}\left({ }^{\circ}\right)$ & $\theta_{\mathrm{r}}\left({ }^{\circ}\right)$ & \\
\hline $20 \mathrm{a}$ & 16 & $0^{*}$ & 72.6 & 59.4 & 40.1 \\
\hline $20 \mathrm{~b}$ & 51 & $0^{*}$ & 108.0 & 72.8 & 18.2 \\
\hline $21 \mathrm{a}$ & 99 & $0^{*}$ & 70.1 & 57.3 & 41.6 \\
\hline $21 b$ & 153 & 151 & 102.6 & 67.7 & 21.4 \\
\hline $22 \mathrm{a}$ & 76 & $0^{*}$ & 68.8 & 52.6 & 43.4 \\
\hline $22 b$ & 152 & $0^{*}$ & 102.5 & 64.0 & 21.5 \\
\hline
\end{tabular}

* Wetted by water.

on the micro-rough hydrophilic aluminium oxide layer. PMMA (sample 20a) is a more polar polymer with a significantl higher surface free energy. But it is interesting that on rough aluminium surfaces the advancing contact angle was lower than the corresponding contact angles for the coated silicon wafer only for the homopolymer (20a) and the fuorine-containing copolymer (20b). In all cases where the copolymers contained additional hydrophilic sequences the advancing contact angles were higher. Corresponding XPS measurements indicated more dense f lms, e.g. for the tert-butyl methacrylate copolymers. The f uorine-containing copolymers 
$21 \mathrm{~b}$ and $22 \mathrm{~b}$ showed very high advancing contact angles of approximately $150^{\circ}$, but the receding contact angles were very different. In the case of sample $21 \mathrm{~b}$ a superhydrophobic behavior according to the Cassie-Baxter model was obtained. On the other hand, sample 22b was wetted by water, which corresponds to the model of Wenzel. Here, the solid/liquid contact area was higher which increases the adhesion forces and, finall, water was able to penetrate the cavities.

\section{Conclusions}

To endow anodically oxidized and roughened aluminium surfaces with a superhydrophobic behavior it was necessary to apply polymethacrylate flms containing non-polar as well as polar sequences. Methacrylate monomers with a hydrophobic side chain were able to decrease the surface free energy of the corresponding polymers. However, such methacrylate polymers did not form dense coatings on micro-rough hydrophilic surfaces. To improve the $\mathrm{f} \mathrm{lm}$ formation properties polar methacrylate monomers were co-polymerized. The self-segregation of the hydrophobic segments to the polymer/air interface, driven by the principle of minimizing the free energy of the complete system, enabled the formation of dense coatings with low surface energy. Thus, original hydrophilic aluminium oxide surfaces changed their surface properties to a superhydrophobic behavior. The anodic oxidation and roughening of the aluminium sheets is suitable to be applied in industrial processes. The polymer coatings can be easily produced in common organic solvents and applied from their solutions by simple dipping or spraying. Neither the aluminium sheet size nor its shape limit their suitability to endow them with superhydrophobic surfaces.

\section{Acknowledgements}

The authors would like to thank the German Ministry of Education and Research (BMBF) for f nancial support (FKZ: 03C0340A-C). We are grateful to B. Schneider and K. Pöschel for their help in the measurement of contact angles.

\section{References}

1. T. Nishino, M. Meguro, N. Katsuhiko, M. Matsushita and Y. Ueda, Langmuir 15, 4321 (1999).

2. R. N. Wenzel, Ind. Eng. Chem. 28, 988 (1936).

3. R. E. Johnson, Jr. and R. H. Dettre, in: Contact Angle, Wettability and Adhesion, Adv. Chem. Ser. No. 43, p. 112, Amer. Chem. Soc. Washington, DC (1964).

4. B. D. Cassie and S. Baxter, Trans. Faraday Soc. 40, 546 (1944).

5. A. Hennig, K. Grundke, R. Frenzel and M. Stamm, Tenside Surfactants Detergents 39, 243 (2002).

6. M. Callies and D. Quéré, Soft Matter 1, 55 (2005).

7. D. Quéré, Rep. Prog. Phys. 68, 2495 (2005).

8. M. Ma and R. M. Hill, Curr. Opin. Colloid Interface Sci. 11, 193 (2006).

9. X. Feng and L. Jiang, Adv. Mater. 18, 3063 (2006). 
10. X. Li, D. Reinhoudt and M. Crego-Calama, Chem. Soc. Rev. 36, 1350 (2007).

11. K. Tsujii, T. Yamamoto, T. Onda and S. Shibuichi, Angew. Chem. Intl. Ed. 36, 1011 (1997).

12. M. Thieme, R. Frenzel, S. Schmidt, F. Simon, A. Hennig, H. Worch, K. Lunkwitz and D. Scharnweber, Adv. Eng. Mater. 3, 691 (2001).

13. M. Thieme, R. Frenzel, V. Hein and H. Worch, Corrosion Sci. Eng. 6, 47 (2003).

14. R. Frenzel, C. Blank, V. Hein, M. Thieme, H. Worch and F. Simon, J. Adhesion Sci. Technol., to be submitted.

15. J. Kijlstra, K. Reihs and A. Klamt, Colloids Surfaces A 206, 521 (2002).

16. S. Ren, S. Yang, Y. Zhao, T. Yu and X. Xiao, Surface Sci. 546, 564 (2003).

17. D. K. Sarkar and M. Farzaneh, in: Proceedings of the 2006 NIST Nanotechnology Conference and Trade Show, Boston, Massachusetts, Vol. 3, pp. 166-169 (2006).

18. D. Pospiech, D. Jehnichen, A. Gottwald, L. Häußler, W. Kollig, A. Janke, S. Schmidt and C. Werner, Surface Coatings Intl. B 86, 43 (2003).

19. R. D. van de Grampel, W. Ming, A. Gildenpfennig, W. J. H. van Gennip, J. Laven, J. W. Niemantsverdriet, H. H. Brongersma, G. de With and R. van der Linde, Langmuir 20, 6344 (2004).

20. M. Wulf, K. Grundke, D. Y. Kwok and A. W. Neumann, J. Appl. Polym. Sci. 77, 2493 (2000).

21. G. Beamson and D. Briggs, High Resolution of Organic Polymers, The Scienta ESCA 300 Database. Wiley \& Sons, Chichester, UK (1992).

22. D. A. Shirley, Phys. Rev. B 5, 4709 (1972).

23. D. Y. Kwok, T. Giezelt, K. Grundke, H.-J. Jacobasch and A. W. Neumann, Langmuir 3, 2880 (1997).

24. K. Grundke, in: Polymer Surfaces and Interfaces, M. Stamm (Ed.), pp. 124-127. Springer, Berlin (2008).

25. D. Y. Kwok and A. W. Neumann, Adv. Colloid Interface Sci. 81, 167 (1999).

26. W. Barthlott and C. Neinhuis, Planta 202, 1 (1997).

27. K. Nielsch, J. Choi, K. Schwirn, R. B. Wehrspohn and U. Gösele, Nano Letters 2, 677 (2002). 